\title{
Editors' Introduction. Futures: Imagining the World of Tomorrow
}

\author{
Roberto Franzini Tibaldeo \\ (Universit Catholique de Louvain, roberto.franzini@uclouvain.be), \\ Cristina Rebuffo \\ (CeSPeC, rebuffocristina@gmail.com), \\ Luisa Maggio \\ (Brussels, luisa_maggio@yahoo.it)
}

From 12 to 17 September 2016 in Cuneo (Italy) took place the $9^{\text {th }}$ edition of the international Summer School organized by the Centro Studi sul Pensiero Contemporaneo (CeSPeC) ${ }^{1}$. The event revolved around the topic of the "future", which was analysed from different interdisciplinary perspectives and gave rise to stimulating conversation. We are grateful to "Ethics in Progress" for accepting to devote this issue to the reflections stemming from the Summer School.

The future is indeed a core issue, since our existential condition is essentially future-oriented. Not only is our present open to future and eager to shape it, but to some extent also the opposite is true: the future we are able to imagine provides us with a hermeneutical lens thanks to which we understand the present and become aware of our duty to gear it towards what is to come.

Events that happened in the last 10-15 years, like the global financial crisis and a certain number of international geopolitical issues (including the terrorist attacks and the migrant crisis), have certainly undermined the Europeans' confidence in their future. On the other hand, we have the impression that recently people have started again to regard their future with increasing optimism. Let us provide some statistical data.

We would like to start with the Perils of Perception released on 5 December 2017 by Ipsos. The survey focuses on the gap between perception and reality in 38 countries. What is at stake is the citizens' capacity to evaluate correctly phenomena. The analysis of the results show people's tendency to depict reality in a gloomier light than required. This relies on factors like the following: a) the appropriation of good news is slower and less effective than the appropriation of bad news; b) optimistic confidence in the future often lacks the support of concrete facts; c) the magnitude of present-day globalised phenomena fosters the generalised tendency to assume worst-case scenarios. In this regard, in order to tackle successfully the abovementioned challenges, it is necessary to regain a certain power over our future, first of all by fighting against the belief that "all is lost".

\footnotetext{
${ }^{1}$ www.cespec.it.
} 
The second survey we wish to quote was published in December 2017 by Pew Research Center under the title Worldwide, People Divided on Whether Life Today Is Better Than in the Past (Pew Research Center 2017). This poll asks people in 38 countries the question: how far do people around the globe think they and others like them have come, compared with 50 years ago? Among the key factors in assessing progress and comparing the present with the past, are the following: those who live in a prosperous country and are more educated are generally optimistic; the same is with the young people, who are more optimistic than their elders; as for the political divides, the supporters of populism often show nostalgia for an idealized past and observe present and future with a critical eye (see for instance Bobbio 1987; Crouch 2004).

Let us finally draw attention to two documents focusing on citizens' expectations of Europe released in 2017 by the European Commission's Eurobarometer. As regards the future of the European Union, the first survey states that "a majority of Europeans are optimistic for the future of the EU" $(57 \%,+7$ percentage points since autumn 2016)2. The second survey underlines an additional feature: solidarity and social equity are perceived as essential elements of the future of Europe, and as values thanks to which the latter will be able to tackle global challenges (European Commission 2017b, 121, 151). Moreover, a slight majority of Europeans are aware that "life of today's children in the EU will be more difficult than the life of those from their own generation (54\%)" (European Commission 2017b, 5). Nevertheless, "more than nine in ten respondents (91\%) agree they are happy with their family life and $64 \%$ are happy with their current occupation. Large majorities also agree they are happy living in the country they currently live in $(89 \%)$ or in the EU (78\%)" (European Commission 2017b, 4).

It is precisely in order to face the current challenges to living together and democracy, that a systematic and constructive reflection on future is necessary. And this is in order to enhance our capacity to conceive and practise new ways of tackling the abovementioned challenges. Indeed, an imaginative and creative enquiry into future should thus enable us to recognise, distinguish and eventually nourish existing signs of the future by fostering their generativity and their capability of creating sociality, promoting solidarity and justice, etc.

With regard to the meaning of "future", about a century ago two emblematic works were published almost simultaneously: The Spirit of Utopia by Ernst Bloch (2000 [or. ed. 1918-1923]) and The Decline of The West by Oswald Spengler (1927 [or. ed. 1918-1922]). Both works help us to understand the framework of the contributions published in this issue.

Shocked by the experience of the World War I, Bloch states the failure of European culture. Far from wanting to resign, Bloch believes it is of

${ }^{2}$ European Commission (2017a, 20; see as well Eurostat 2012). 
fundamental importance to propose a reflection capable of future. His ambition to contribute to the renewal of individual existence and of living together requires that a new fundamental principle be found, which he identifies in the concept of utopia: "To find it, to find the right thing, for which it is worthy to live, to be organized, and to have time: that is why we go, why we cut new, metaphysically constitutive paths, summon what is not, build into the blue, and build ourselves into the blue, and there seek the true, the real, where the merely factual disappears - incipit vita nova"(Bloch 2000,3). As already for Thomas More who coined the term ${ }^{3}$, for Bloch "utopia" does not refer to something inexistent or impossible because it lacks any real basis or is deprived of any possibility of realization, but to something which does notyet-exist and is not-yet-perceptible, something which is thus not clearly determinable in itself, but possible, something which is ultimately capable of indicating a way of achieving a far but attainable goal. Moreover, the great "utopian" works of the $16^{\text {th }}$ and $17^{\text {th }}$ century authored by Tommaso Campanella, Francesco Patrizi, Francis Bacon, and James Harrington reflect on the political relevance of utopia and provide unique accounts of ideal, perfect and just "no places", as paradigms and standards of social, political, and religious reformation of the coeval real world.

The successive developments of Bloch's reflection identify in Marxism the historical-material basis of utopia (Bloch 1986-1995 [or. ed. 1954-1959]), a choice that especially in the light of the collapse of ideologies during the $20^{\text {th }}$ Century - including the Marxist-Communist - now sounds quite impracticable and unrealistic. Nevertheless, Bloch's merit is undoubtedly to have reevaluated the lesson of More, who employed the notion of utopia to point out the centrality of the future to the human being's constitution. Indeed, this notion is of twofold importance: firstly, it highlights that the human being is characterised by the inseparable relationship between imagination, reflection, experience and action; secondly, utopia is endowed with normative relevance, since what distinguishes us is the "imaginative engagement with a model which can modify our attitudes and even qualify our conduct" (Baker-Smith 2014).

Let us take a look at Spengler's The Decline of the West. As a first remark, we have to observe how this title is in a certain way misleading: indeed, what has started to decline is not the Western culture alone. According to Spengler, all cultures as such share the vital cyclicality of childhood-youth-maturity-old age. What is interesting about Spengler's view is the concept of

${ }^{3}$ The word "utopia" (from the Greek oú "no" and tótos "place", thus "no place" viz. "non-existing place") was coined by Thomas More and refers to the unreal and ideal state described in his book Libellus vere aureus nec minus salutaris quam festivus de optimo reipublicae statu, deque de nova Insula Utopia [A Truly Golden Account of the Best State of a Commonwealth and of the New Island of Utopia], which was first published by the Leuven printer Thierry Martens in 1516 (More 1995). 
"pseudomorphosis", which he employs to explain how some historical periods (such as late-antiquity) are characterized by a mixture of heterogeneous and reciprocally conflictual cultural elements. To sum up, "pseudomorphosis" is a principle used in mineralogy, according to which when a new crystalline substance occupies the cavity left in a geological layer from crystals that have disintegrated, it is forced by the mould to take a crystalline form that is not its own. Without a thorough chemical analysis the observer would be led to consider it as a crystal of the original type, incurring in the error of not recognizing the originality of the first with respect to the latter. By extending this naturalistic principle to the hermeneutics of history, Spengler hypothesizes that in some historical moments heterogeneous and innovative cultural elements appear in forms left from the past that is disintegrating forms that however continue to exert compulsion and violence on innovative ferments, which cannot freely deploy their originality and creative power (Jonas 2001, Cacciatore 2005).

What is the relevance of Bloch and Spengler's thinking to the current reflection, which assumes that the present time and its crisis need a reflection on the future? To avoid misunderstandings, we wish to underline our refusal of those interpretations of the present that see in it an inevitable destiny of decline (in this sense, we certainly reject Spengler's metaphysics of history and the distinction he introduces between superior and inferior cultures). The reason why we believe that both Bloch's utopian perspective and Spengler's dichotomal view are still interesting nowadays, is that they provide inspiration as regards our duty to recognise and nourish possible signs of the future which are to be found in our present. Not having yet the possibility to fully unfold themselves due to the resistance and inertia of the existing systems, those signs risk to be crushed by the latter or to exhaust their own innovative charge. How to prevent this? Moreover, it seems to us that the liveliness of these signs of future - along with their conviction of being sooner or later able to unfold themselves with greater freedom, proactivity, and creativity - is itself the strongest evidence against any rhetoric of decadence, inertia and uncritical acceptance of the present. How can we recognize and support these promising signals, which appear in present-day cultural, social, economic, and political phenomena? How can we help these signals develop into cultural, reflective, widespread practises? How can we give a special contribution to enhancing young peoples' desire and hope for the future?

We thought of providing the contributors to the current issue of "Ethics in Progress" with a constellation of conceptual guidelines (creativity, generativity, innovation, interpersonal relations, diversity, justice, and education), which were meant to inspire their reflections. At the same time, these concepts could to be understood as facets of a hermeneutical and reflective lens to be employed in order to assess, recognize, and orient 
possible signs and practises aiming at social, cultural, political, pedagogical renewal.

Here is a summary of the contributors' reflections, along with the criteria by which we decided to arrange them. The first section gathers some philosophical reflections on the notions of temporality and especially of the future. In his essay Luigi Laino argues that the future is the main temporal dimension of human action and gains this result by comparing Ernst Cassirer's "animal symbolicum" and André Leroi-Gourhan's "Homo technologicus". Bianca Bellini proposes a phenomenological enquiry into the way human beings understand time. In our multilayer experience of time we move towards an effort of shaping the future and towards an effort of comprehending the past. Francesca Peruzzotti's article draws a connection between Jacques Derrida's and Jean-Luc Marion's negative theology, thanks to which they contribute to a new definition of subjectivity in a postmetaphysical age and clarify which future possibilities are still available for a history which is truly open-ended and irreducible to being a simple continuation of the present. Finally, Gemma Serrano claims that the digital culture is modelling a new temporal affect in our lives. This phenomenon is related to the massive employ of digital memory together with the progressive disappearance of our capacity to remember and hope. Yet, this new condition of ours is not at odds with creativity, which still has a critical role to play and can successfully trickle through the cracks of our altered present.

The contributions to the second section analyse the impact of specific topics related to science and technology on future. The aim of Alessandro De Cesaris' article is to analyse the relationship between creativity, freedom and future in the contemporary society. The author tries to answer the question about how people may attain creativity in the digital era. Sure enough, such question deals with a reflection on the future, since the latter corresponds to the concept of something new still to come, something entailing an increment of possibilities. Moving from this definition, the question is how people may succeed in creating something new in today's society, where nothing seems to have the chance of being truly new. Next comes the contribution by Stéphane Grumbach, which focuses on the societal role currently played by digital platforms. They shape indeed a new world which does not correspond to geographic maps but to complex and wide networks controlling various sectors at a global scale ensuring intermediation with algorithmic means. Such new geography entails a new grammar for those territories in order to preserve social justice, which is potentially in danger due to the massive accumulation of data on human activities and its processing ("big data") by digital platforms themselves. The third article of the second section is authored by Silvano Tagliagambe: in opposition to those who believe that data and numbers entrusted to the machines' management would be sufficient in taking decisions, the author asserts that especially in the field of ethics 
choices are to be taken not only on the basis of numbers but also on suppositions, hypothesis and interpretations of data, and that the project and the context we move from to approach data is essential. This is especially clear if we focus on the question regarding landscape, because in this case an interdisciplinary approach considering not only statistics and numerical data, but also abilities and other competences is necessary. In his article Jelson Oliveira intends to analyse how the current employ of technology represents a threat to biodiversity, and this is due to trends related to reduction and standardization, which in the long run may cause the collapse of life itself. By referring to Hans Jonas' thinking, the author argues that it is important and necessary to avoid the nihilistic perils of present-day technology, whose aim is to design a new future where the control of life would be complete, as envisaged - among others - by transhumanists. In the last contribution to this section Nicola Cerutti proposes an experimental and theoretical analysis of social dilemmas related to environmental issues, whose possible consequences affect the management of natural resources, especially when this involves a large number of actors. In this case, strategies encouraging cooperative and reasonable behaviour and the development of policies and regulations are needed: this contribution reviews the existing literature and draws attention to experimental tests related to this topic.

The last section includes contributions focusing on the future from an anthropological, psychological, moral, political and pedagogical point of view. Moving from the current discouraging framework, characterized by the crisis of values, narcissism and the ineptitude to take care of other humans, Gian Sandro Lerda tries to outline a new existential framework for our future. In this regard, he highlights the importance of relationships based on attachment, trust, desire, care, and creativity. According to the author, it is important to promote and support educational activities pivoted on these fundamental experiences and feelings, in order to preserve both the individual's and the community's wellness and self-realization. The following three essays focus on Georg Lind's philosophical-psychological proposal, known as the "Konstanz Method for Dilemma Discussion" (KMDD). Roma Kriaučiūnienë's contribution is actually a review of Lind's book How to teach Morality. Promoting Deliberation and Discussion, Reducing Violence and Deceit (2016). The article is a commentary of book's main topic, namely that morality can be taught. The following article by Ewa Nowak and Adrianna Urbańska focuses on the necessity of educative prevention to face the growth of aggressiveness and violence in nowadays societies. The kind of prevention based on KMDD actually succeeds in dealing with interpersonal conflicts and represents a reasonable alternative to political oppression and institutional penalties. At the base of such practice there is the belief that reinforcing social and moral competences is the strongest relief to face the growth of violence. In line with the two previous contributions, Joanna Dutka aims at fostering a 
future free from interpersonal violence through education focusing on moral and democratic competences. This effort is likely to prevent violence, especially in the domestic environment. The achievement of this goal requires women's self-empowerment and the growth of gender equality. Both goals can be successfully achieved thanks to Lind's KMDD. Federico Zamengo outlines the role of adult educators in the postmodern society, where they need to accept the hard challenges posed by complexity in order to be able to appear credible to youngsters. The article is addressed to those who play an educational role both in formal and non-formal/informal contexts. This enquiry entails understanding, at first, what it means to be an adult in an intergenerational perspective, since we are always adults in comparison to someone who is not adult yet. The last two articles offer to readers two case studies. Silvia Bevilacqua and Pierpaolo Casarin describe a philosophical experience carried out in a secondary school in Mondovì (Italy). According to the educational proposal known as "Philosophy for Children" (P4C), philosophy is understood as a practice, an experience, a creative and collective exercise of thinking. More specifically, in their article the authors report the innovative perspective of a "Post-Philosophy for Children". Finally, moving from the description of some Chinese rural and urban situations, Shaogang Yang, Sharon To and Charles C. Helwig's essay aims at demonstrating that environments (such as family, school, and so on) structured in a democratic way and taking charge of children's needs of autonomy contribute to their psychological health and well-being.

\section{Literature}

Baker-Smith, D. 2014. Thomas More, in Stanford Encyclopedia of Philosophy. Available at: https://plato.stanford.edu/entries/thomas-more/.

Bloch, E. 1986-1995. The Principle of Hope. 3 vols. Cambridge (MA): MIT Press. Originally published in German in 1954-59.

Bloch, E. 2000. The Spirit of Utopia. Stanford: Stanford University Press. Originally published in German in 1918-23.

Bobbio, N. 1987. The Future of Democracy. Cambridge: Polity.

Cacciatore, F. M. 2005. Indagini su Oswald Spengler. Soveria Mannelli: Rubbettino.

Crouch, C. 2004. Post-Democracy. Cambridge: Polity.

European Commission. 2017a. Standard Eurobarometer 88 - Public Opinion in the European Union. Autumn. Available at: http://ec.europa.eu/commfrontoffice/publicopinion/index.cfm/Surve y/getSurveyDetail/instruments/STANDARD/surveyKy/2143.

European Commission. 2017b. Special Eurobarometer 467 - Future of Europe, December.

Available

at: 
http://ec.europa.eu/commfrontoffice/publicopinion/index.cfm/Surve $\mathrm{y} /$ getSurveyDetail/instruments/SPECIAL/surveyKy/2179.

Eurostat. 2012. Figures for the Future: 20 Years of Sustainable Development in Europe? Available at: http://ec.europa.eu/eurostat/documents/3217494/5735463/KS-3212-152-EN.PDF.

Ipsos. 2017. Perils of Perception. Available at: https://www.ipsos.com/itit/perils-perception-2017-lindagine-sul-pericolo-delle-percezioni.

Jonas, H. 2001. The Gnostic Religion. Boston: Beacon Press.

Lind, G. 2016. How to Teach Morality. Promoting Deliberation and Discussion, Reducing Violence and Deceit. Berlin: Logos.

More, Th. 1995. Utopia: Latin Text and English Translation. Ed. by G. M. Logan, R. M. Adams, \& C. Miller. Cambridge: Cambridge University Press.

Pew Research Center. 2017. Worldwide, People Divided on Whether Life Today Is Better Than in the Past. Available at: http://www.pewglobal.org/2017/12/05/worldwide-people-dividedon-whether-life-today-is-better-than-in-the-past/.

Spengler, 0. 1927. The Decline of the West. New York: Knopf. Originally published in German in 1918-1922. Available at: https://archive.org/stream/Decline-Of-The-West-OswaldSpengler/Decline Of The West\#page/n1/mode/2up. 


\author{
Roberto Franzini Tibaldeo \\ (Louvain-la-Neuve, Belgium, roberto.franzini@uclouvain.be), \\ Cristina Rebuffo \\ (Cuneo, Italy, rebuffocristina@gmail.com), \\ Luisa Maggio \\ (Brussels, Belgium, luisa_maggio@yahoo.it) \\ Editors' Introduction. Futures: Imagining the World of Tomorrow
}

\begin{abstract}
From 12 to 17 September 2016 in Cuneo (Italy) took place the $9^{\text {th }}$ edition of the international Summer School organized by the Centro Studi sul Pensiero Contemporaneo (CeSPeC). The event revolved around the topic of the "future", which was analysed from different interdisciplinary perspectives and gave rise to stimulating conversation. In this introduction we provide an overview of the topic and of the reflections stemming from that event.
\end{abstract}

Keywords: future, hope, Europe, democracy

Ethics in Progress (ISSN 2084-9257). Vol. 8 (2017). No. 1, Art. \#1, pp. 3-12.

Creative Commons BY-SA 3.0

Doi: 10.14746/eip.2017.1.1 